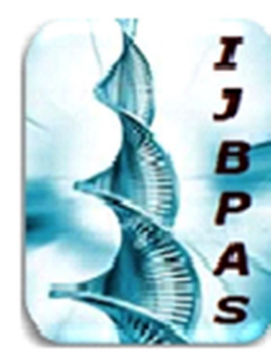

International Journal of Biology, Pharmacy and Allied Seiences (IJBPAS) 'A Bridge Betusen Caboratory and QRendo'

www.ijbpas.com

\title{
SMART CITIES AND EMBEDDED IOT SENSOR SYSTEMS TO IMPROVE THE PERFORMANCE OF THE AUTOMATED ENVIRONMENT
}

\section{KANNADASAN B ${ }^{1^{*}}$, DHEERAJ RANE ${ }^{2}$, SATHISH KUMAR PENCHALA ${ }^{3}$, RANJAN WALIA $^{4}$, SONU KUMAR ${ }^{5}$ AND SELVAN. ${ }^{6}$}

1: Assistant Professor, Civil Engineering, B.S.Abdur Rahman Crescent Institute of Science and Technology, GST Road, Vandalur Chennai - 600048

2: Associate Professor and Head, Computer Science and Engineering, Indore Institute of Science and Technology, Indore, Madhya Pradesh-453331, India

3: Associate Professor \& Head, Artificial Intelligence and Machine Learning, Indore Institute of Science and Technology, Indore, Madhya Pradesh-453331, India

4: Associate Professor in Electrical Engineering at Model Institute of Engineering and Technology, Jammu, J \& K, India

5: National Level Coordinator, Speak Out, Ignite, Bhumi, Chennai, India

6: Professor in Electrical and Electronics Engineering at Erode Sengunthar Engineering College, Perundurai, Erode, Tamilnadu

*Corresponding Author: Kannadasan B; E Mail: kdasan9@gmail.com

Received $20^{\text {th }}$ July 2021; Revised 22 ${ }^{\text {nd }}$ Aug. 2021; Accepted $30^{\text {th }}$ Sept. 2021; Available online $1^{\text {st }}$ Nov. 2021 https://doi.org/10.31032/IJBPAS/2021/10.11.1055

\section{ABSTRACT}

Metropolitan centers are a popular topic just today, and they're quickly becoming as the preferred paradigm for modern living development in the present. Within its global academia, these are just a few books that realistically approach the problem of intelligent cities, and much less that are interdisciplinary. Standalone screens are unable to provide the complex understanding requirements of intelligent cities, necessitating the use for embedding sensing 
systems to bring the concept of intelligent city to reality. That essay discusses the notion of intelligent city and linked sonar networks.Despite that fact that much data includes a spatial component, the study calls for an interdisciplinary approach to smart city study, in particular surveyors should perform a part.

\section{Keywords: Sensing; Urban area; IoT; Innovation; Automated Environment}

\section{INTRODUCTION}

The term "smart city" has become increasingly common in governmental, financial, academic, and everyday conversations. In most instances, the benefits of smart cities to the environment and the people are stressed, cementing the notion of career progression as one of the greatest answers to humankind's future problems. The evolution of the notion of smart cities begins with interconnected sensing devices [1]. The purpose of this paper is to give a critical evaluation of the problem of sensing devices in smart cities.

This detector is an electric device that translates physical characteristics into an electric signal that may be read by people or recorded in a self-contained device. Lighting, gravity, warmth, moisture, and a variety of other factors are some of the indications for types of sensors [2]. Under Micro-ElectroMechanical Technologies (MEMS), embedded sensor programs integrate its use of several complementing detectors [3]. In the context of technology, it is necessary to directly link sensors through a wireless connection to a central entity that receives and analyzes data, which is why they are termed wireless sensor networks [4]. This is significant when municipalities are far too complicated for a particular sensing device to provide the information requirements required for good management [5].

The globe has been experiencing urbanization and population expansion over the last few generations. In 2010, urbanization housed $50 \%$ of the worldwide people on just $1 \%$ of the earth's natural geographic region, and this number is predicted to increase to $75 \%$, or 6 billion people, by 2050 [6]. There would be even greater economic inequities throughout the globe as the city grows. On a global scale, resource limitations, global warming, and pollutants will become increasingly severe [7]. Metropolis will be extremely vulnerable owing to the dense population, putting additional strain on assets such as soil, shelter, fresh water, and electricity [8]. Successful implementation of megacities and provision of essential services to inhabitants, 
such as transportation, security, water system, and electricity, would be a unique challenge. The creation of smart cities information and technology is the solution to these problems. Smart cities could use less energy, freshwater, and emit less $\mathrm{CO} 2$ as a result of their use of technologies [9]. It really would raise the standard of living through improving the use of current facilities, providing new services to the residents, and improving the use of existing facilities [10].

There's, however, a distinct viewpoint on the origins of the notion and the necessity for smart buildings. Even though the notion of "smart growth" dates back to the early late 1990s, it was only after the economic crisis of 2008 that smart cities began to gain traction. Several towns had demonstrated interest in productivity expansion at the time, and IBM saw the significant market because of its computers goods, while the previously cited motivations remained second. During the economic meltdown of 2008-2009, urban areas recognized they would have to fight with each other like have never [11]. It wasn't just the rivalry with business neighbors on a nationwide level, but also competitiveness with colleagues all over the globe, thanks to the Web and global production systems. It wasn't just a battle for terms of employment generation; it was also a battle for the Generation Y and Generation Z (those born just after the 1980s) who supporters believed would have been the architects of new financial strength [12]. This involvement in smart cities is essentially linked with their marketing or reputation, as well as their capacity to recruit such individuals, the socalled artistic classes.

\section{Smart City elements}

Several concepts of smart cities first from examined research were split into two tiers by the writers in [13]. Smart cities are indeed a type of efficient and sustainable urban growth based on the notion of new urbanism, according to one theory. Smart cities are viewed as a technical phenomenon in the second set of articles. Because this original study technique is similar to that of the former, this will be discussed in greater depth. Information and communications technology (ICT), IoT, Wireless Sensors network (WSNs), and other technologies are all part of the technical infrastructure of smart cities. Several levels of the smart city/IoT technical architecture are 1) devices, 2) networks, and 3) programs. Devices collect information via the networks and deliver it to a CPU, from which choices about the application level are formed [14]. Platforms can be introduced as a distinct 
level of the design, where its information is recorded [15]. (Figure 1).

Security Models

Application Layer
Analyze and evaluate the huge amounts of data
using Smart Agriculture, Industrial Monitoring,
Public Security, Smart Governance, Smart
Health care, Smart Transportation, Smart
Energy.
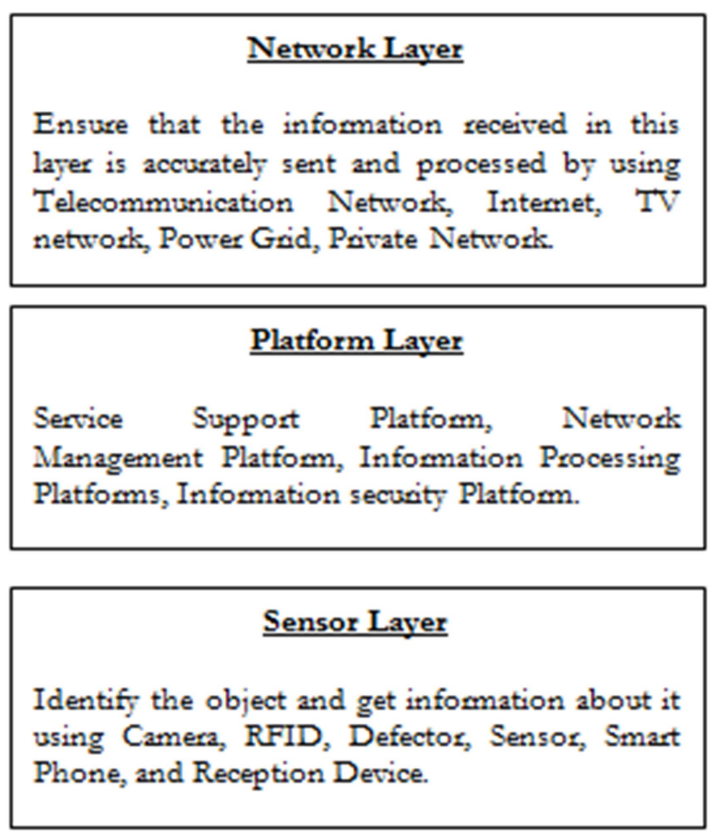

Figure 1: Smart city technological architecture

In [16] contains several schemas of smart cities' network infrastructure, particularly includes exchanges amongst smart city players such as residents, municipal agencies, and service providers. Smart cities' infrastructure includes devices and networking (Figure 2). Metropolitan technologies or characteristics that necessitate smart administration are referred to as application level. According to the writers to which the audience is directed, whose number is usually among 3 and 8 . These IBM researchers consider a model that divides cities into five levels: natural environments, infrastructures, commodities, activities, and welfare structures. Every stratum is categorized in much more detail. (Figure 3).

[17] proposes a simplified metropolitan model of the system with 3 broad components: financial, political, and ecological. Public management and financial 
institutions make improve the economic dimension, and people make up the social element, while materials and effective element. ICT connects the parts of a city of improvements make up the environmental the future. (Figure 4).

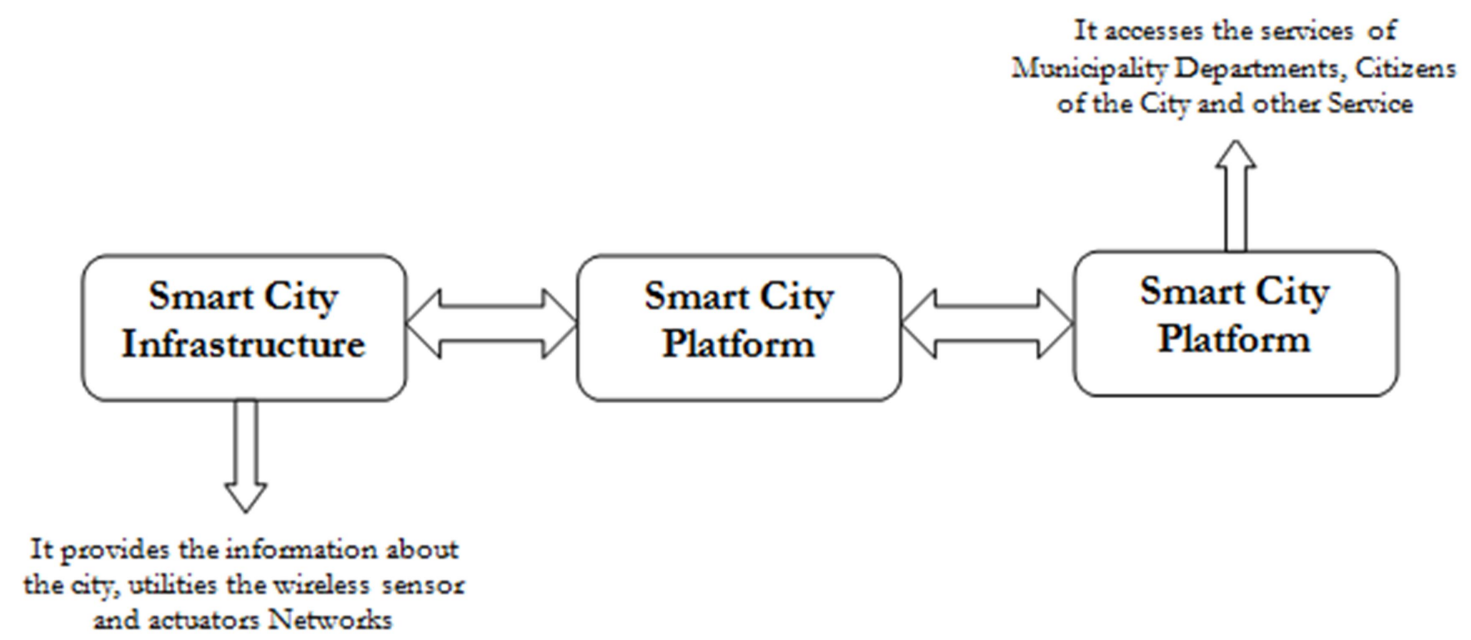

Figure 2: Interactions between smart city actors

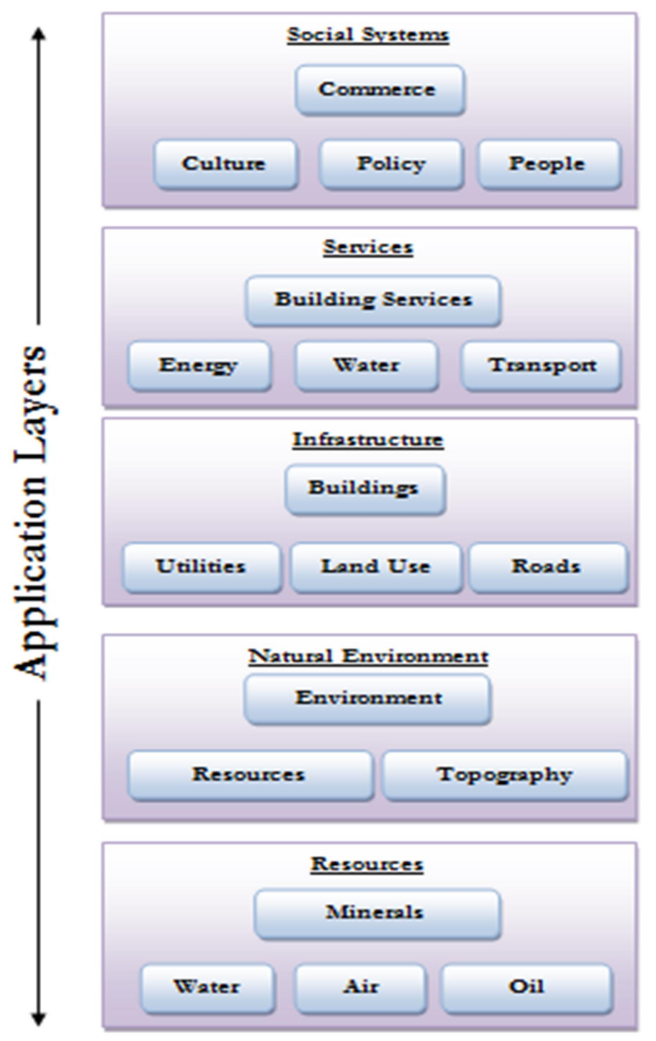

Figure 3: Smart city application layers 


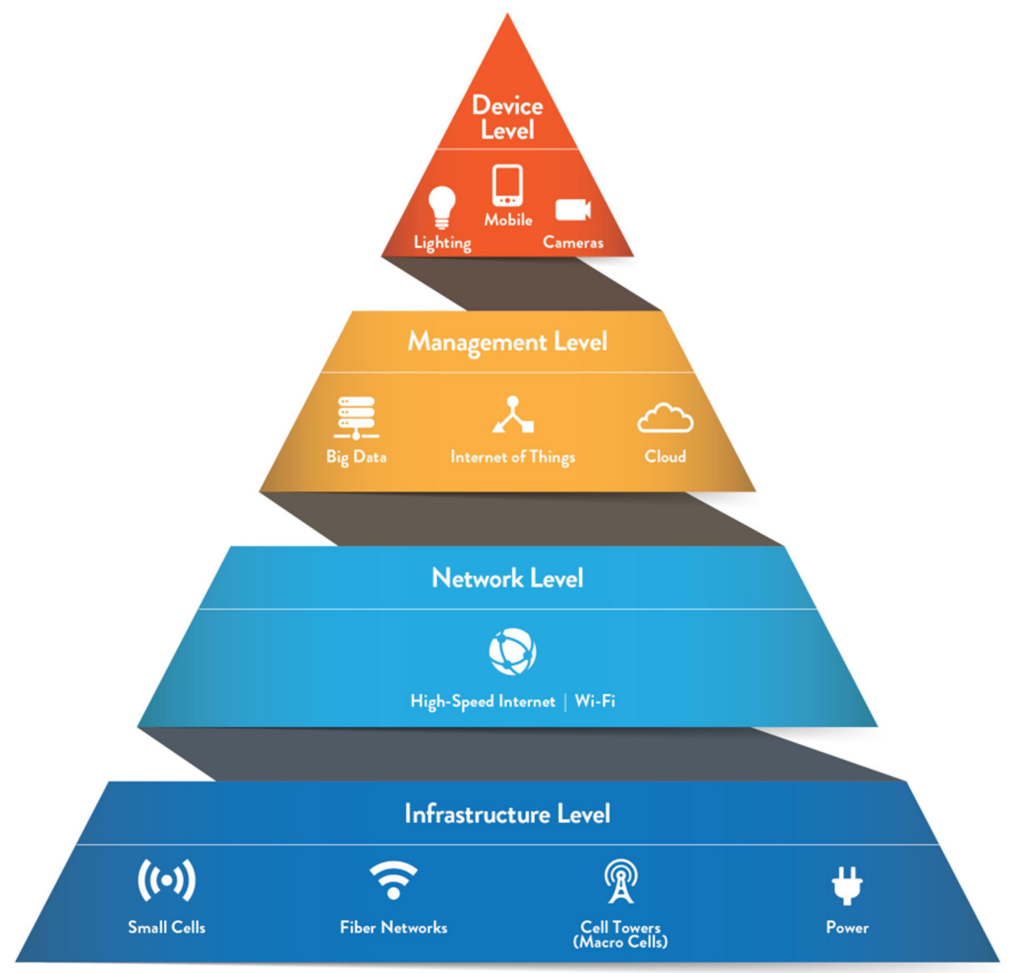

\section{Performance Evaluation}

That smart-city idea is currently much too broad and complicated to be completely implemented across all urban structures. As a result, the most common method of smart cities, in reality, would be through projects focused on certain city components. Such initiatives are quite varied, and success measurement in smart cities initiatives is heavily reliant on the issue that the program is addressing. As a result, there have been no conventional critical success factors for evaluating the projected impact that development ought to have on municipal administration or resident standard of living, necessitating the development of individual key performance indicators for each development. Observations may be obtained in [18], which provides an in-depth look at the major metrics of European smart cities. This has been noted that smart city rating standards can also be universally applied since they are dependent on publishers and funders, datasets, indicator utilization, system configuration, and the complexity of the findings.

\section{Integrated Sensor Systems}

Every advanced control system relies heavily on detectors. A method improves as a result of its surroundings, as well as to make a control method conscious of its surroundings, it is generally outfitted with various sensors in which it gathers the necessary data. Moreover, it characterizes its 
surroundings with the relevant characteristics and adjusts its actions appropriately [19]. According to other writers, urban areas often are photographed as groupings of equipment throughout many measurements which are attached thru various channels as well as provide statistical information about individuals and equipment motions in terms of the provision of choices about the cultural and psychosocial structure of the city. The high significance of sensing devices for smart buildings is reflected in smart city analytical frameworks, in which they are frequently proposed as the initial layer. Devices must be widely placed and networked so that the gathered information can be transferred to a core of the network, wherein smart choices may be made depending on the statistics. This presents a variety of difficulties. To begin, a communication network must be in existence as these devices to interact with others. Secondly, how can this information be aggregated and processed in the most positive manner possible?

Devices are split into three groups in modern urban geo-sensing ideas and terminology: in situ technological detectors, distant technological detectors, and personal sensor systems. Those three groups intersect to some extent, making them difficult to differentiate from one another. Another distinction here between situ and distant technical detectors is that even in situ devices measure in the scanner's physical vicinity, and technical support services devices measure at a distance, as the names indicate. Human-generated observations are used to acquire data from human sensors. Perceived environmental views, social media updates, cellular phone conversations, and texts and emails, and physiological responses through external sensing devices are all examples. This concept assumes that there is a clear separation between people who create data and individuals who carry "ambient sensors" to monitor the various environment.

The concept that detectors should be deployed in the format of a sensor network is widely recognized. It's a collection of instruments that really can represent a similar power supply, as well as a communications and computing component. It is feasible to collect diverse data from numerous devices at the same time in this manner. Due to the huge amount of sensor networks that must be put in a city of the future, it's indeed critical to consider their scale and energy usage. Surveying also plays a vital role in urban planning gadgets networks. To provide comprehensive data which will then help to make choices and possibly even view the 
results to target consumers based on one's considering the location, it is needed to ascertain the spatial dimension for the vast bulk of different sensors, in additament to their quantitative elements. Besides providing geographical support for that other information, cities face a slew of extra spatially embedded problems that must be addressed promptly, and the usage of GNSS devices are the most commonly proposed option nowadays.

This IoT idea is especially relevant when discussing the connectivity between sensor networks. Within the current Web architecture, it relates to the connectivity of individually identified embedded systems. Generally, the Internet of Things (IoT) is projected to provide advanced connectivity of objects, networks, and functions that extends outside machine-to-machine interactions (M2M) and spans a wide range of subjects and purposes. Sensor networks ought to be energy efficient \& electronically connected to form a Wireless Sensor Network, according to the IoT idea (WSN). This would have been a technique to prevent the substantial costs and issues associated with system electrical wiring.

\section{Applications}

Also with an early fast spike in the volume of automobiles on the road, there is indeed a greater need for effective transportation administration to minimize traffic congestion and improve incoming traffic, particularly at junctions. As urban areas become more capable of being increased accessibility with a wide range of mobile and stationary sensors are connected through wireless routers, a broader choice of urban planning Intelligent Transport systems (ITS) applications becomes available. Responsive personalized locations, responsive automotive GPS tracking, clever asset tracking, and traffic control, highway occurrence recognition, traffic shaping, speed control via intelligent communication with alongside the road control mechanisms, situationally servicing, parking space assistance, the person driving track, and improved drivers protection are just a few of the amenities available.

Recording devices provide a much less invasive (but less precise) and much more complex technique. When contrasted to the previously past mentioned techniques, those alternatives are not much more appealing since webcams are easier to set up and need less upkeep. Security cameras could also be utilized for smart transport systems in cases where they are already established. Numerous conventional CCTV cameras and personal computers (PCs) were used to test 
things in various situations (e.g. airports and tunnels). The primary disadvantage of machine vision-based techniques is that their effectiveness is highly dependent on external factors like illumination, occluded, and temperature. For vehicle detection in a dark situation, lamp posts and stoplights can be employed, as cars can be identified by comparing the distances among their beams.

\section{Smart Grid}

A dependable and real-time surveillance system is essential in the smart grid to provide solutions immediately when natural disasters or accidents happen, preventing electricity disruption and outages. As a result, sophisticated surveillance and sensor systems are required to ensure realtime reaction from the power system. Due to their minimal price, ease of deployment, adaptability, and collected information via parallelization, wireless sensor nodes can be utilized instead of conventional forms of communication. That collected data by such systems may subsequently be utilized to provide approved organizations with comments on the grid's consistency and reliability. Continuous surveillance of high voltage transmission lines, for example, is an essential sensor function in the smart grid. Facilities guarantee that electricity supply is now within safe levels by checking the connections. For example, technologies like STAMP assess the warmth, sagging, and pressure of an overhead transmission line on a real-time basis and use this information to evaluate the route's status or healthiness. Detectors can be used for close surveillance of a family's income power usage and therefore give reductions and a much more flexible billing process, in addition to controlling and measuring the network.

\section{DISCUSSION}

Differences of opinion over nomenclature and meanings arise from the fact that true urban areas have yet to emerge in practice, with much of the discussion focusing on concepts and incomplete implementation. The role of information communication technology in the more efficient leadership of infrastructure facilities and the ecosystem is emphasized in most definitions of smart buildings. It must be noted, nevertheless, that urban areas are indeed a tool for enhancing people's and societies' standard of living. Communities that are merely clever in terms of economic growth aren't smart whatsoever if they disregard their citizens' social situations.

Despite the recent state of technical advancement, there are indeed significant technical and fundamental issues with sensing devices. Certain issues with sensing 
reliability and the intelligence devices collect, identifying the set of devices needed for a specific operation, integrating a significant volume and variety of data, device power source, and the geographical element of the records, for instance, persist. Although it is advised to utilize as many instruments as necessary for collecting data, emphasis must be made on the quality of information obtained and its usefulness. It's not a good idea to have too much duplicate info. In that instance, the quality of air may not be as varied as it should be for each structure. This might produce an excessive amount of information, which would clog up storage and slowing down the whole system without improving the credibility of the results. In furthermore, the function and performance of the detectors must be considered while choosing them (price to accuracy ratio). Is that essential to put a detector on every potted plant to check humidity and alert you when it's underwatering it? Will the same sum of funds be put in both sound and earthquake detectors if noise pollution becomes less significant than seismic events?

Moreover, when a significant multitude of distinct devices is used, the problem of information homogeneity arises. These acquired data will aid the centralized server in creating good judgments, resulting in improved municipal governance. To produce original judgments, a large amount of data in multiple forms, as well as diverse temporal and spatial levels, must be employed. Because man's capacity to make excellent and logical judgments is dependent on human reasoning and intellect, artificial intelligence (AI) has been suggested as a solution for computer-based judgment. Even though some Ai applications are now accessible, the AI idea is still evolving and will take a bit of time before something truly comes back to life [16]. Norms should indeed be established to address the issues of file format variations and interconnectivity among both various systems together within the city of the future. The major worldwide standardization bodies are closely monitoring the growth and challenges surrounding smart cities, and relevant standards will be in the works.

Although wireless connectivity is commonly acknowledged as a method for sensor information and monitoring devices in smart cities, the issue of monitor power sources persists. Almost all writers now see the CMOS batteries as a sensor's source of power, however, this does not imply that it is the ultimate or wisest choice. It would also be inconvenient to just have to replace the batteries once while if we were talking about 
a big number of sensor nodes. Braided electricity supply is particularly troublesome since it necessitates expensive infrastructural development and complicates the instrument placement. That notion of cordless transmitting power emerges as a potential future workable solution. The performance of the detectors might be improved as a result of the fact because various operations might no more be constrained to prolong battery capacity.

A low degree of interdisciplinarity, i.e. collaboration amongst professionals from different scientific branches, may be observed after reviewing and evaluating all of the gathered material on smart cities. Researchers are primarily concerned with addressing issues that are known to themselves, and they approach challenges from the perspective of their particular field of study. Urban areas, generally, and urban areas, in particular, have too many issues to be handled by a particular scientific area or industry. This is especially true when it comes to security concerns, which typically trump other elements of smart city development. The healthy ratio among participants and components of an urban planning design must be ensured by a reasonable balance in science disciplines and occupations engaging in the development of intelligent cities.

\section{CONCLUSION}

Urban areas are becoming a widely debated issue, not just in scholarly communities as well as in the press. The creation of the urban planning idea, on either hand, should indeed be left to specialists and researchers, with a difference drawn among truly smart alternatives and those that merely employ contemporary technology as part of interconnected sensing devices and subsequent updates. However, it becomes even more beneficial to incorporate as many partners as feasible who are end customers inside the execution of this idea. Furthermore, growth should indeed be tailored to each city's distinct physical, financial, cultural, as well as other qualities. This topic of smart cities and radar systems within cities may be approached in a variety of ways, depending on the person's career or scientific discipline. That fact that somebody is from of the metropolis, thus the challenges of this metropolitan area are nearer and obvious to a person, might sometimes influence their thinking on smart cities. As a result, additional work must be done to enhance interconnections and collaboration in the investigation of urban planning 
challenges to generate increasingly complete and superior answers.

\section{REFERENCES}

[1] Sharma A, Singh PK, Kumar Y. An integrated fire detection system using IoT and image processing technique for smart cities. Sustainable Cities and Society. 2020 Oct 1; 61: 102332.

[2] Radu LD. Disruptive technologies in smart cities: A survey on current trends and challenges. Smart Cities. 2020 Sep; 3(3): 1022-38.

[3] Radu LD. Disruptive technologies in smart cities: A survey on current trends and challenges. Smart Cities. 2020 Sep; 3(3): 1022-38.

[4] Dr.P.Sivakumar, "Analytical framework to build predictive and optimization function from manufacturing industry sensor data using cross-sectional sharing", Big Data,2021 (SCI)

[5] Dr.P.Sivakumar, "Improved Resource management and utilization based on a fog-cloud computing system with IoT incorporated with Classifier systems", Microprocessors and Microsystems, Jan 2021 (SCI).

[6] Ranjeeth, S., Latchoumi, T. P., \& Paul, P. V. (2020). Role of gender on academic performance based on different parameters: Data from secondary school education. Data in brief, 29, 105257.

[7] Venkata Pavan, M., Karnan, B., \&Latchoumi, T. P. (2021). PLA-Cu reinforced composite filament: Preparation and flexural property printed at different machining conditions. Advanced Composite Materials, https://doi.org/10.1080/09243046.2021, 1 918608.

[8] Desouza KC, Hunter M, Jacob B, Yigitcanlar T. Pathways to the making of prosperous smart cities: An exploratory study on the best practice. Journal of urban technology. 2020 Jul 2; 27(3): 3-2.

[9] Schürholz D, Kubler S, Zaslavsky A. Artificial intelligence-enabled contextaware air quality prediction for smart cities. Journal of Cleaner Production. 2020 Oct 20; 271: 121941.

[10] Chen J, Ramanathan L, Alazab M. Holistic big data integrated artificial intelligent modeling to improve privacy and security in data management of smart cities. Microprocessors and Microsystems. 2021 Mar 1; 81: 103722.

[11] Wirtz BW, Müller WM, Schmidt F. Public smart service provision in smart cities: A case-study-based approach. International Journal of Public Administration. 2020 Apr 25; 43(6): 499-516.

[12] Hernandez-de-Menendez M, Díaz CA, Morales-Menendez R. Educational experiences with Generation Z . International Journal on Interactive 
Design and Manufacturing (IJIDeM). 2020 Sep; 14(3): 847-59.

[13] Pekica G. Expectations of Generation Z When Entering the Job Market in Croatia.

[14] Arshad J, Tariq R, Saleem S, Rehman AU, Munir H, AmiriGolilarz N, Saleem A. Intelligent greenhouse monitoring and control scheme: An arrangement of Sensors Raspberry Pi based Embedded System and IoT platform. Indian Journal of Science and Technology. $2020 \mathrm{Jul} 31$; 13(27): 2811-22.

[15] Lozoya-Santos JD, Félix-Herrán LC, Tudón-Martínez JC, Vargas-Martinez A, Ramirez-Mendoza RA. Design and implementation of an iot-oriented strain smart sensor with exploratory capabilities on energy harvesting and magnetorheological elastomer transducers. Applied Sciences. 2020 Jan; 10(12): 4387.

[16] Kandris D, Nakas C, Vomvas D, Koulouras G. Applications of wireless sensor networks: an up-to-date survey.
Applied System Innovation. 2020 Mar; 3(1): 14 .

[17] Pelorosso R. Modeling and urban planning: A systematic review of performance-based approaches Sustainable cities and society. 2020 Jan 1; 52: 101867.

[18] Cacciola P, Tombari A. A stochastic ground motion model for the urban environment. Probabilistic Engineering Mechanics. 2020 Jan 1; 59: 103026.

[19] Niu G, Yi X, Chen C, Li X, Han D, Yan B, Huang M, Ying G. A novel effluent quality predicting model based on genetic-deep belief network algorithm for cleaner production in fullscale paper-making wastewater treatment. Journal of Cleaner Production. 2020 Aug 20; 265: 121787.

[20] Satpathy S, Mohan P, Das S, Debbarma S. A new healthcare diagnosis system using an IoT-based fuzzy classifier with FPGA. The Journal of Supercomputing. 2020 Aug; 76(8): 5849-61. 